\title{
Pattern of vigorous physical activity among Egyptian freshmen university students
}

\author{
Nadia Abd El-Hamed Montasser ${ }^{1}$ (MD) \\ Abdel-Hady El-Gilany Abd El- Fattah ${ }^{2}$ (MD) \\ Randah Mohamad Helal ${ }^{3}$ (MD) \\ 1 Professor of Public Health, Department of Community Medicine, College of Medicine, Mansoura University, Egypt \\ ${ }^{2}$ Professor of Public Health, Department of Community Medicine, College of Medicine, Mansoura University, Egypt \\ ${ }^{3}$ Lecturer of Public Health, Department of Community Medicine, College of Medicine, Mansoura University, Egypt \\ Correspondence to: Randah Mohamad Helal (ranhel2000@yahoo.com)
}

\begin{abstract}
Objectives. To highlight the pattern of vigorous physical activity among freshmen university students and to evaluate the association between sociodemographic factors, perceived barriers, support factors, sedentary behaviours and body mass index.

Methods. A cross-sectional study was conducted on Mansoura University students at the beginning of the academic year 2008 2009. A total of 500 freshmen students were selected by systematic random sample. Participants responded to the short form of International Physical Activity Questionnaire and other questions. Results. The study revealed that the prevalence of vigorous activity among the students was $9.8 \%(\mathrm{~N}=49)$ versus $90.2 \%(\mathrm{~N}=451)$ for mild and moderate activity. Body-related barriers were significantly higher among those reporting mild and moderate activities as shyness from others when doing exercise $(6.9 \%$ versus $0.0 \%)$ and shyness from body looks in front of people (14.6\% versus $4.1 \%)$. Lack of equipment was also perceived to be a barrier ( $31.0 \%$ versus $16.3 \%$ ), for those doing mild to moderate versus vigorous, respectively. A significantly higher proportion of persons doing vigorous activity reported the influence of support factors such as perceived benefit for health $(53.1 \%$ versus $33.7 \%)$, encouragement from others ( $53.1 \%$ versus $30.4 \%$ ) and participation from others $(51.0 \%$ versus $23.9 \%$ ), compared with the more sedentary students. The majority of both groups spent $<4$ hours daily in front of a computer, but the overall proportion was significantly higher among those only reporting mild and moderate activity $(88.0 \%$ versus $63.3 \%)$.

Conclusion. The prevalence of most of the barriers studied was higher among those reporting mild and moderate activities and support factors were higher among those reporting vigorous activity. These results highlight the importance of environmental factors, social norms and intra-personal factors in determining the pattern of activity among Egyptian freshmen university students.
\end{abstract}

\section{Introduction}

The benefits of regularly participating in physical activity, through casual or organised activities or programmes, seeking to improve fitness, mental well-being and social relationships, are well recognised. ${ }^{1}$ Physically inactive lifestyles present a major health problem to the populations of developed and developing nations, contributing to chronic diseases and psychological distress. ${ }^{2}$ Although young people are more physically active than adults, the worldwide increase in overweight among youth has raised concerns about the adequacy of habitual activity levels among children and adolescents. The Centers for Disease Control and Prevention reported in 2000 that nearly half of American youth aged $12-21$ years are not vigorously active on a regular basis. ${ }^{3}$ Further, youth become increasingly less active as grades in school increases, with the most dramatic declines occurring during adolescence (ages 15 - 19 years) and young adulthood (ages $20-25$ years). ${ }^{4}$ Even in adolescence, ${ }^{5}$ in the transition to university, and more specifically during the period of study at university, there is a decrease in the practice of moderate to vigorous physical activity. ${ }^{6}$

Irwin, ${ }^{7}$ in his systematic review on participation in physical activity amongst university students (19 studies from 27 countries, not including Egypt) concluded that less than one-half of university students in USA and Canada were sufficiently active to gain a health benefit. Also Musharrafieh et al..$^{8}$ found that $26.4 \%$ of university students in Lebanon engaged in regular physical exercise. Conversely, Abdullah et al. ${ }^{9}$ found that two-thirds of Chinese university students were physically active. In 2011, the American College Health Association ${ }^{10}$ reported that college students as a population are physically inactive, with only $20 \%$ reporting participation in moderate physical activity and $30 \%$ in vigorous physical activity on a regular basis from 2008 to 2010 with slight variation over years. In Egypt, the only available study of physical activity among university students was done by Abolfotouh et al. ${ }^{11}$ This study was conducted among 600 students attending Alexandria University hostels and reported that $33.8 \%$ of the studied sample were physically inactive.

Barriers to physical activity have been examined across a variety of populations. Although findings revealed that as barriers increased, physical activity decreased in youth and adult populations, the findings have been inconsistent in adolescent populations. ${ }^{12}$ Body consciousness has been shown to be a barrier for female adolescents in the general population. ${ }^{13}$ Lack of time has been the greatest obstacle to physical activity in adolescent students. ${ }^{14}$ Also the weather, class assignments and the lack of interest or just the desire to do any other activity, have been among the most commonly mentioned barriers to physical activity by university students in the study carried by Sanz and Ponce. ${ }^{15}$ The lack of social and institutional support, as well as the physical environment, were the main barriers found by Gyurcsik et al. ${ }^{16}$

The aim of our study was to describe the pattern of vigorous physical activity among Egyptian freshmen university students and to evaluate the association between physical activity, 
sociodemographic determinants, barriers, support factors, sedentary behaviours and BMI.

\section{Methods \\ Locality}

The study was carried out in Mansoura University, Egypt during the beginning of the academic year 2008 - 2009. Mansoura University was founded in 1972 in Mansoura city, Egypt and is one of the biggest public Egyptian universities. The main campus is located in Mansoura city. It comprises 13 faculties: medicine, education, science, pharmacy, dentistry, commerce, law, engineering, agriculture, nursing, veterinary medicine, physical education; as well as computer science and information systems. Four faculties are located off campus, namely arts, special education, tourism and hotels, and kindergartens.

\section{Population}

The target population included newly attending students (freshmen) of the practical sectors in Mansoura University (practical faculties of medicine, pharmacy, nursing, veterinary medicine, dentistry and the other practical faculties such as science, agriculture, computer and information, engineering), attending a routine medical checkup that is done for the first-year students in the university. The practical sectors were chosen as they were more accessible, and as first years, the students still live with their families. They represent different geographical and socio-economic strata of the community. The pattern of physical activity studied reflects physical activity during vacation time (not during the academic year). Most of these students would make use of public transportation, with a minority having access to private cars.

\section{Sample size determination}

There are approximately 6000 first-year students. We based our sample size on an expected prevalence for vigorous physical activity in Arab young adults of $11.3 \%$, previously reported by Al-Hazzaa. ${ }^{17}$ Using Epi-Info version 6 with $11.3 \%$ as the expected prevalence, and $8.5 \%$ as the minimal prevalence, we estimated that we would require a sample of at least 454 subjects, and increased this to 500 to be more representative. The students were selected according to a systematic sampling strategy, one in every 11 students.

\section{Measures and data management}

Demographic attributes, different forms of activity, barriers, support factors and other sedentary behaviours were assessed using a selfadministered questionnaire presented in Arabic languages after obtaining oral consent from the participants. Participants reported their age, gender and residence. Socio-economic variables ${ }^{18}$ included parents' education and occupations, per capita monthly income in Egyptian pounds, family size, crowding index, and presence of audiovisual sets. Participants self-reported their frequency and duration of their physical activity during the previous week using the short form International Physical Activity Questionnaire. ${ }^{19}$ Physical activity was classified as follows:

- low - no activity is reported or some activity is reported but not enough to meet physical activity levels 2 or 3

- moderate - any of the following 3 criteria: 3 or more days of vigorous activity of at least 20 minutes per day or 5 or more days of moderate-intensity activity and/or walking of at least 30 minutes per day or 5 or more days of any combination of walking, moderate or vigorous intensity activities achieving a minimum of at least 600 MET (Metabolic Equivalent)minutes/week
Table I. General demographic and behavioural characteristics of the studied group

\begin{tabular}{lll}
\hline Studied group characters & $N$ & $\%$
\end{tabular}

Sociodemographic characteristics

Gender

Male

$210 \quad 42.0 \%$

Female

290

$58.5 \%$

Age (years)

Mean \pm SD

$17.7 \pm 0.7$

Residence

$\begin{array}{lll}\text { Urban } & 305 & 60.6 \% \\ \text { Rural } & 197 & 39.4 \%\end{array}$

Socioeconomic standard

$\begin{array}{lll}\text { High } & 331 & 66.2 \% \\ \text { Middle } & 155 & 31.0 \% \\ \text { Low } & 14 & 2.8 \%\end{array}$

\section{Activity pattern}

Practised vigorous activity $\quad 49$

Practised mild and moderate activity $\quad 451 \quad 90.2 \%$

BMI

Underweight

Normal weight 311

Overweight

$62.2 \%$

Obese

Sedentary behaviour

TV watching

$\begin{array}{lll}<4 \mathrm{~h} & 369 & 73.8 \% \\ \geq 4 \mathrm{~h} & 131 & 26.2 \%\end{array}$

Computer use

$<4 \mathrm{~h}$

428

$85.6 \%$

$\geq 4 \mathrm{~h}$

72

$14.4 \%$

Music hearing

139

$27.8 \%$

Sleep hours

$\begin{array}{lll}<8 \mathrm{~h} & 428 & 85.6 \% \\ \geq 8 \mathrm{~h} & 72 & 14.4 \%\end{array}$

- high - any one of the following 2 criteria: vigorous-intensity activity on at least 3 days and accumulating at least 1500 MET-minutes/week or 7 or more days of any combination of walking, moderate-vigorous intensity activities accumulating at least $3000 \mathrm{MET}$-minutes/week.

One MET is the energy (oxygen) used by the body as a person sits quietly, perhaps while talking on the phone or reading a book. MET-minute/week is computed by multiplying the MET score of an activity by the minutes performed. The MET score differs according to the activity, for example walking $=3.3 \mathrm{METs}$, for moderate physical activity = 4.0 METs and for vigorous activity = 8.0 METs.

We obtained measures of height and weight. Height measurements were to the nearest $0.5 \mathrm{~cm}$ without shoes and weight was measured to the nearest $0.1 \mathrm{~kg}$ with light clothes. Body mass index (BMI) was calculated as weight in kilograms divided by heightin meters squared. Individuals with a BMI $<18.5$ are considered underweight, those with BMI of $18.5-24.9$ are considered normal 
Table II. Distribution of the studied group physical activity according to their personal, social, behavioural characteristics and their BMI

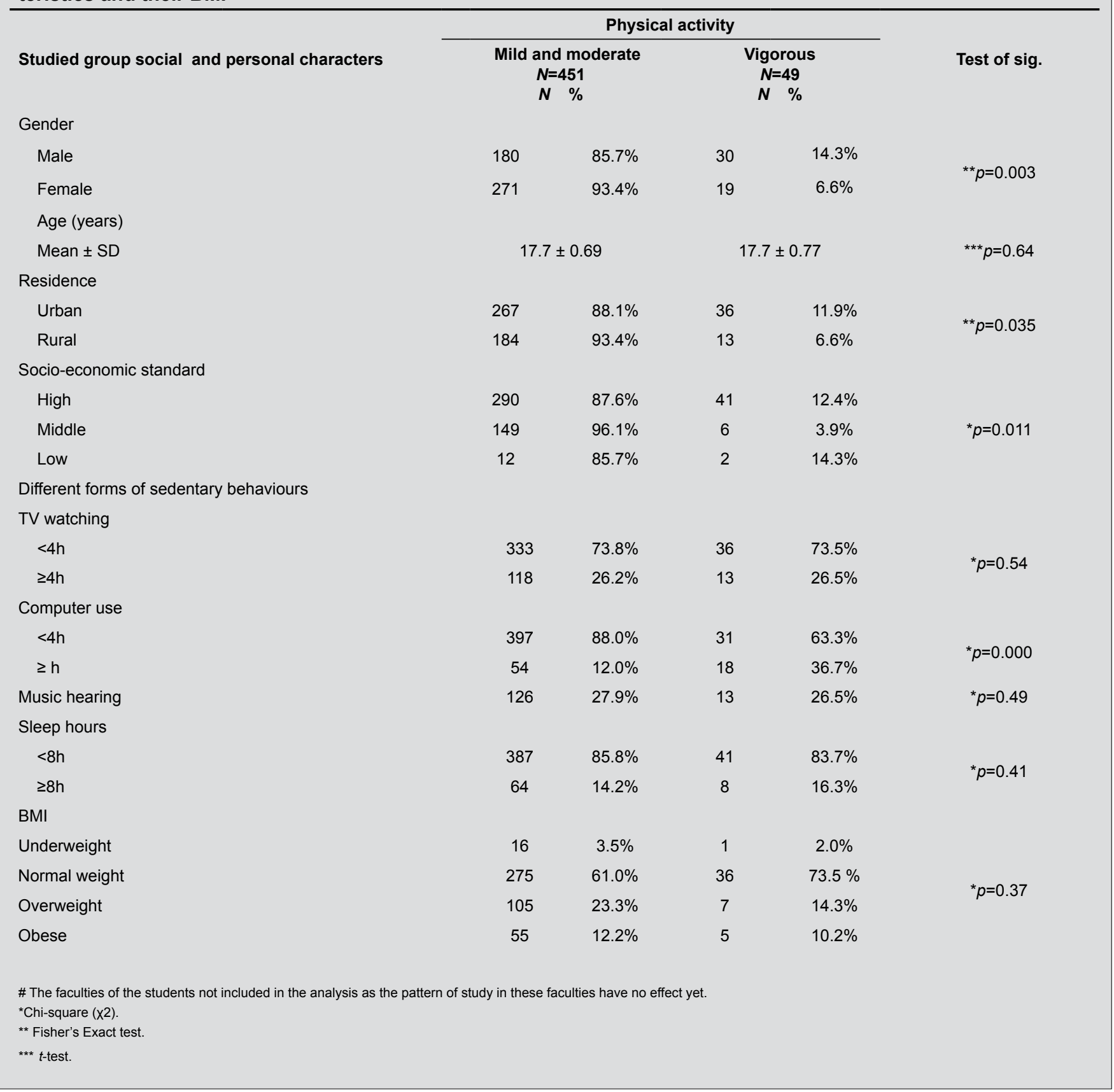

weight, individuals with BMI of 25 - 29.9 are considered overweight, while individuals with a BMI of 30 or more are considered obese. ${ }^{20}$

\section{Barriers and support factors to physical activity}

Data on barriers to and factors in support of physical activity were collected. These were grouped according to whether they were related to physical limitations, convenience, available resource, social factors, and fitness-related issues. Participants also reported the total hours they spent watching television, playing video games, in front of computers or using the Internet and if they prefer listening to music during studying lessons.

\section{Statistics}

A nested case-control study was carried out between students with mild/moderate activity and those with vigorous activity. The com- pleted questionnaires were subjected to revision and the collected data were coded, processed and analysed through SPSS (Statistical Package for Social Sciences) (Standard version release 16.0). The Chi-square and Fisher's exact tests were used for testing significance of categorical data, as appropriate. Student's t-test was used for continuous data as age. The significance level was considered at $p \leq 0.05$.

\section{Results}

Table I presents the characteristics of the sample, $42.0 \%$ of whom were male and $58.0 \%$ of whom were female, with a mean age of $17.7 \pm 0.7$ years. About two-thirds of studied groups were from urban areas and had high socio-economic status. Only $9.8 \%(\mathrm{~N}=49)$ of the students practised vigorous activity but $62.2 \%$ of the students had 
Table III. Distribution of the studied group physical activity according to different types of barriers to physical activity (PA)

\section{Different barriers to \\ physical activity}

\section{Body-related}

Shyness from others when doing exercise

Shyness from body looks in front of people

\section{Convenience}

Lack of time

Inconvenient weather

\section{Resource}

Lack of convenient place

Lack of interest in PA

Lack of facilities

Lack of knowledge

Social

Lack of participation from friends

Lack of skilled friends

Bad behaviour of friends

\section{Fitness}

Too overweight to do PA

$\mathrm{PA}$ is uncomfortable or difficult

\section{Types of physical activity}

$\begin{array}{cc}\text { Mild and moderate } & \text { Vigorous } \\ N=451 & N=49 \\ N \% & N \%\end{array}$

Test of sig.

$\begin{array}{lllll}31 & 6.9 \% & 0 & 0.0 \% & { }^{*} p=0.037 \\ 66 & 14.6 \% & 2 & 4.1 \% & { }^{*} p=0.024 \\ 292 & 64.7 \% & 30 & 61.2 \% & { }^{*} p=0.37 \\ 30 & 6.7 \% & 4 & 8.2 \% & { }^{* *} p=0.43\end{array}$

$\begin{array}{lllll}142 & 31.5 \% & 10 & 20.4 \% & { }^{*} p=0.072 \\ 71 & 15.7 \% & 5 & 10.2 \% & { }^{*} p=0.21 \\ 140 & 31.0 \% & 8 & 16.3 \% & { }^{*} p=0.02 \\ 78 & 17.3 \% & 4 & 8.2 \% & { }^{* *} p=0.068\end{array}$

$\begin{array}{lllll}29 & 6.4 \% & 5 & 10.2 \% & { }^{*} p=0.23 \\ 15 & 3.3 \% & 1 & 2.0 \% & { }^{* *} p=0.52 \\ 10 & 2.2 \% & 1 & 2.0 \% & { }^{* *} p=0.7 \\ 11 & 2.4 \% & 0 & 0.0 \% & { }^{* *} p=0.32 \\ 78 & 17.3 \% & 5 & 10.2 \% & { }^{* *} p=0.14\end{array}$

${ }^{*}$ Chi-square $\left(X^{2}\right)$.

${ }^{\star *}$ Fisher's Exact test.

normal BMI, $26.2 \%(\mathrm{~N}=131)$ spent more than 4 hours in front of the television but only $14.4 \%(\mathrm{~N}=72)$ spent more than 4 hours in front of the computer. Also $14.4 \%(\mathrm{~N}=72)$ of the studied group slept more than 8 hours per day and $27.8 \%(\mathrm{~N}=139)$ preferred listening to music.

As shown in Table II, the age of the sample ranged between 17 and 20 years, with a mean age of $(17.7 \pm 0.7$ years), with slight differences between groups. Only $6.6 \%$ of the women reported vigorous activity compared with $14.3 \%$ of men. Vigorous activity was more prevalent among urban inhabitants $(11.9 \%)$ than rural ones $(6.6 \%)(p=0.035)$. However, a nearly equal prevalence of vigorous activity was reported among low and high social class but much lower rates were reported among middle social class $(p=0.011)$.

By studying the sedentary behaviours, it was found that the only significant difference between groups was for computer use, which was higher among those reporting only mild and moderate activity. For the rest of sedentary behaviours no significant differences were detected.

Although no significant difference was detected between both groups regarding BMI, it was observed that normal-weight students represented the majority among both groups with a higher per cent among the students reporting vigorous activity. Overweight and obesity were slightly more prevalent among those reporting only mild and moderate activity.

Barriers to physical activity are presented in Table III. Certain barriers were significantly more common among those reporting only mild and moderate activities such as body-related barriers which included shyness from others when doing exercise $(6.9 \%$ versus $0.0 \%)$ and shyness from body looks in front of people $(14.6 \%$ versus $4.1 \%$ ) and one of the resource barriers, which was lack of equipment $(31.0 \%$ versus $16.3 \%)$. Other resource barriers, convenience barriers, social barriers and fitness barriers showed no significant differences between groups. However, bad weather and lack of participation by friends were barriers more commonly reported for those students participating in vigorous physical activity.

Table IV shows the distribution of different support factors for physical activity among the studied groups. Those students that engaged in vigorous physical activity more commonly reported perceived benefit for health, encouragement from others and participation from others, as support factors for participation.

\section{Discussion}

Many young people do not engage in sufficient levels of physical activity to afford the associated health benefits. The 2005 Youth Risk Behavior Surveillance Survey results indicate that only $36 \%$ of American high school students participate in at least 60 minutes per day of physical activity on a regular basis. ${ }^{21}$ Moreover, recent data from the National Health and Nutrition Examination Survey (NHANES) indicate that $33 \%$ of American teenagers are unfit and that this is setting the stage for health problems later in life. ${ }^{22}$

The results of the present study showed that only $9.8 \%$ of the students practised vigorous activity. Nearly equal rates were reported 


\section{Table IV. Distribution of the studied group physical activity according to support factors to physical activity}

\begin{tabular}{|c|c|c|c|c|c|}
\hline \multirow[b]{2}{*}{ Different support factors to physical activity } & \multicolumn{4}{|c|}{ Physical activity } & \multirow[b]{2}{*}{ Test of sig. $\left(x^{2}\right)$} \\
\hline & \multicolumn{2}{|c|}{$\begin{array}{l}\text { Mild and moderate } \\
N=451\end{array}$} & \multicolumn{2}{|c|}{$\begin{array}{c}\text { Vigorous } \\
N=49\end{array}$} & \\
\hline Perceived benefit for health & 152 & $33.7 \%$ & 26 & $53.1 \%$ & $p=0.006$ \\
\hline Encouragement from others & 137 & $30.4 \%$ & 26 & $53.1 \%$ & $p=0.001$ \\
\hline Transportation availability & 66 & $14.6 \%$ & 10 & $20.4 \%$ & $p=0.192$ \\
\hline Participation by others & 108 & $23.9 \%$ & 24 & $51.0 \%$ & $p=0.000$ \\
\hline
\end{tabular}

by Lemos et al.. ${ }^{23}$ who used the IPAQ as he found that $8.4 \%$ of the university students in Spain were vigorously active. Higher rates of activity reported in other studies that assessed vigorous activity as the activity that 'made you sweat or breathe hard' engaged in for 20 minutes or more (e.g. Staten et al. ${ }^{24}$ ) reported that $39 \%$ of university students in one of USA public universities were vigorously physically active. Porter et al., ${ }^{25}$ found that $44.3 \%$ of South African university students reported having engaged in vigorous physical activity on 5 or more of the 7 days preceding the survey. The variation of these prevalences among different countries is a reflection of the different socio-economic status, availability of facilities and also the different tools used for the assessment.

Females reported less vigorous activity than males, which is similar to the results described by others. ${ }^{26,27}$ This may be due to lack of time associated with their responsibilities and care-giving duties to their mothers and family and also the body-centered issues related to their shyness and religious issues in Islamic society. Also in Egyptian society, many women rarely practise physical activity except for weight loss.

Concerning residence, vigorous activity was more prevalent among urban inhabitants than rural inhabitants, and this may be due to the availability of resources such as equipped clubs, gymnasium halls and sidewalks. Conversely, nearly equal rates of vigorous activity were reported among low and high social class, but much lower rates were reported among middle social class. This may be explained, in part, as higher classes have greater access to facilities for physical activity with lower barriers. Lower social classes lack access to advanced technology and luxury items that promote sedentary behavior; they also lack private cars for transportation, making them more dependent on public and human-powered transport. This is in contrast with what was reported by Landsbaugh, ${ }^{28}$ who found that as socio-economic status level increased, the amount of physical activity increased and the amount of time reported participating in vigorous activities increased.

The majority of both groups were sitting in front of computer less than 4 hours daily. Nevertheless, the time spent in front of the computer was higher among those reporting participation only in mild and moderate activity. Naomi et al. ${ }^{29}$ reported that sedentary behaviour is a distinct category of activity and is not merely the absence of vigorous exercise. Also Samdal et al. ${ }^{30}$ reported that it is possible for adolescents to obtain sufficient physical activity and to spend time watching TV.

There was no significant difference in BMI between groups, which is in agreement with Osman et al., ${ }^{31}$ who found no significant relation between levels of physical activity and overweight status among obese subjects. However, Inas ${ }^{32}$ reported that increased intensity is correlated with a lower BMI.

Body-related barriers and lack of facilities were significantly higher among those reporting mild and moderate activities. These findings are consistent with a recent study that found that the number of recreational facilities was positively associated with physical activity in a national sample of adolescents. ${ }^{33}$ However, a more recent review concluded there was no consistent association between activity and availability of facilities. ${ }^{34}$ Lack of time was slightly higher among those reporting mild and moderate activities, which is similar to that reported by Salmon et al. ${ }^{35}$ Bowles et al. ${ }^{36}$ suggested that perceived lack of time as a barrier could, in fact, be a reflection of a lack of self-motivation rather than a legitimate obstacle to regular participation in physical activities. Also, most social and fitness barriers were slightly higher among those reporting mild and moderate activities. This is in agreement with Zlot et al. ${ }^{37}$ Also Ball et al. ${ }^{38}$ reported that being overweight can also be perceived as a significant barrier to physical activity.

Most of the support factors for physical activity were significantly higher among those reporting vigorous activities. This is in agreement with McNeill et al. ${ }^{39}$ Also Norman et al. ${ }^{40}$ stated that family support is an important modifiable factor for reducing sedentary behaviour in children and adolescents.

\section{Limitations}

This study had many limitations. It is cross-sectional, and as such causal inferences for both barriers and support factors cannot be made. In addition, it was based on self-report measures of physical activity. Finally, we opted to evaluate only leisure-time physical activities, therefore individuals who did not meet the physical activity guidelines in this study may have been active in other domains (occupation, commuting and housework).

\section{Conclusion and recommendations}

Low levels of leisure-time vigorous physical activity were found among freshmen students in the current study. There was a positive relationship between the number of perceived barriers and physical inactivity. However, the support factors were strongly related to vigorous activity. In order to increase leisure-time physical activity, policymakers should focus their interventions on strategies designed to increase awareness of particular aspects of physical activity, which in turn may help individuals to overcome the perceived barriers to physical activity that were detected in this study. Health education programmes should stress the benefits of physical activity, different ways of practising physical activity, including walking, and providing information concerning the recommended levels of physical activity. Availability of modest clothing designed for physical activity, especially for women, may decrease shyness in this group of students. Also, the lack of availability of facilities was a barrier for activities, which may be overcome by encouraging the students to visit the Olympic Village in the university. This facility has a subsidised programme of activities running throughout the year, including tennis, squash, football, swimming, boxing and others. University pro- 
grammes should encourage team building and sport competitions between students. Programmes should also encourage students to decrease their weight, as overweight and obesity appeared to have an impact on activity.

\section{REFERENCES}

1. Crone D, Smith A, Gough B. 'I feel at one, totally alive and totally happy': a psycho-social explanation of the physical activity and mental health relationships. Health Educ Res 2005;20:600-611.

2. Skidmore PML, Yarnell JWG. The obesity epidemic: Prospects for prevention. Q J Med 2004;97:817-825

3. CDC (Centers for Disease Control and Prevention). Youth risk behavior surveillance summaries. MMWR 2000;49(SS-5):1-96.

4. Malina RM. Adherence to physical activity from childhood to adulthood: A perspective from tracking studies. Aust Psychol 2001;53:346-355.

5. Park H, Kim N. Predicting factors of physical activity in adolescents: A systematic review. Asian Nurs Res 2008;2(2):113-128.

6. Han JL, Dinger MK, Hull HR, Randall NB, Heesch KC, Fields DA. Changes in women's physical activity during the transition to college. Am J Health Educ 2008;39:194-199.

7. Irwin JD. Prevalence of university students' sufficient physical activity: A systematic review. Percept Mot Skills 2004;98(1):927-943.

8. Musharrafieh $\mathrm{U}$, Tamim $\mathrm{H}$, Rahi A, et al. Determinant of university students physical exercise: a study from Lebanon. Int $\mathrm{J}$ Public Health 2008;53(4):208-213.

9. Abdullah AS, Wong CM, Yam HK, Fielding R. Factors related to non-participation in physical activity among the students in Hong Kong. Int J Sports Med 2005;26(7):611-615.

10. American College Health Association. American College Health Association-National College Health Assessment (ACHA-NCHA) Web Summary. http://www.acha-ncha.org/reports ACHA-NCHAll.html. (last accessed May 2011)

11. Abolfotouh MA, Bassiouni M, Fayyad R Ch. Health-related lifestyles and risk behaviours among students living in Alexandria University hostels. EMHJ 2007;13(2):376-391.

12. O'dea JA. Why do kids eat healthful food? Perceived benefits of and barriers to healthful eating and physical activity among children and adolescents. J Am Diet Assoc 2003;103(4):497-501.

13. Marion F, Brian E, Richard I, et al. Overweight children's barriers to and support for physical activity. Obes Res 2003:11(2): 238-246.

14. Wang D, Ou CQ, Chen MY, Duan N. Health-promoting lifestyles of university students in Mainland China. BMC Public Health 2009;9:379.

15. Sanz E, Ponce de León A. La necesidad de educar la dimensión del ocio físico-deportivo. Propuesta surgida de un estudio centrado en una comunidad universitaria. Támden, Didáctica de la Educación Física 2006;20:7388.

16. Gyurcsik NC, Spink KS, Bray SR, Chad K, Kwan M. An ecologically based examination of barriers to physical activity in students from grade seven through first-year university. J Adolesc Health Care 2006;38:704-711.

17. Al-Hazzaa MH. Health-enhancing physical activity among Saudi adults using the International Physical Activity Questionnaire (IPAQ). Public Health Nutr 2007;10(1):59-64

18. Fahmy S, El-Sherbini A. Determining sample parameter for social classifications for health research. Bull High Inst Public Health 1983;13(5):1-14

19. www.lpaq.ki.se

20. WHO (World Health Organization). Controlling the global obesity epidemic, Geneva: World Health Organization, 2003.
21. CDC (Centers for Disease Control and Prevention). Youth Risk Behavior Surveillance - United States (2006). MMWR 2006;55(SS-5):1-108.

22. Carnethon M, Gulati M, Greenland P. Prevalence and cardiovascular disease correlates of low cardiorespiratory fitness in adolescents and adults. JAMA 2005;294:2981-2988.

23. Lemos $\mathrm{C}$, Vargas $\mathrm{O}$, Sanchez $\mathrm{H}$, Cruz N. Chronic back pain and physical activity in students of health occupations. Rev Soc Esp Dolor 2009;16(8):429-436.

24. Staten RR, Miller K, Noland MP, Rayens MK. College students' physical activity: application of an ecological perspective. American Journal of Health Studies. Wntr-Spring 2005 FindArticles com. Accessible at 17 May, 2011. http://findarticles.com/p/articles/mi_m0CTG/is_1-2_20/ai_n27869280/)

25. Porter K, Johnson P, Petrillo J. Priority health behaviors among south african undergraduate students. IEJHE 2009;12:222-243.

26. Gómez M, Ruiz F, García ME, Flores G, Barbero G. Razones que influyen en la inactividad físico-deportiva en la Educación Secundaria Post Obligatoria. Retos. Nuevas tendencias en Educación Física, Deporte y Recreación 2008; 14:80-85

27. Yahia N, Abdallah A, Achkar A, Rizk S. Physical activity and smoking habits in relation to weight status among lebanese university students. Int $J$ Health Res 2010;3(1):21-27.

28. Landsbaugh JR. A longitudinal study examining the relation of physical activity on weight status during adolescence. Thesis submitted to the Graduate Faculty of Education in partial fulfillment of the requirements for the degree of Doctor of Philosophy, University of Pittsburgh; 2007,56-61.

29. Naomi H, Andrew S, David R, Jane W. Trends in physical activity and sedentary behavior in adolescence: Ethnic and socioeconomic differences. $\mathrm{Br}$ J Sports Med 2007;41:140-144

30. Samdal O, Tynjälä J, Roberts S, Villberg B. World trends in vigorous physical activity and tv watching of adolescents from 1986 to 2002 in seven European Countries. Eur J Public Health 2007;17(3):242-248.

31. Osman G, Eduardo S, Betania A, et al. Overweight and obesity among adolescents from Mexico And Egypt. Arch Med Res 2006:37(4):535-542.

32. Inas R. Structural estimation of caloric intake, exercise, smoking, and obesity. Q Rev Econ Finance 2006;46(2):268-283

33. Gordon-Larsen P, Nelson MC, Page P, Popkin BM. Inequality in the built environment underlies key health disparities in physical activity and obesity. Pediatrics 2006;117:417-424.

34. Ferreira I, van der Horst K, Wendel-Vos W, Kremers S, van Lenthe FJ, Brug J. Environmental correlates of physical activity in youth - a review and update. Obes Rev 2007;8:129-154

35. Salmon J, Owen N, Crawford D, Bauman A, Sallis JF. Physical activity and sedentary behavior: A Population-based study of barriers, enjoyment, and preference. Health Psychol 2003;22:178-188.

36. Bowles HR, Morrow JR, Leonard BL, Hawkins M, Couzelis PM. The association between physical activity behavior and commonly reported barriers in a work-site population. Res Q Exerc Sport 2002;73:464-470.

37. Zlot Al, Librett J, Buchner D, Schmid T. Environmental, transportation, social, and time barriers to physical activity. J Phys Act Health 2006;3:15-21.

38. Ball K, Crawford D, Owen N. Too fat to exercise? Obesity as a barrier to physical activity. Aust N Z J Public Health 2000;24:331-333.

39. McNeill LH, Wyrwich KW, Brownson RC, Clark EM, Kreuter MW. Individual, social environmental and physical environmental influences on physical activity among black and white adults: A structural equation analysis. Ann Behav Med 2006;31(1):36-44

40. Norman GJ, Schmid BA, Sallis JF, Calfas KJ, Patrick K. Psychosocial and environmental correlates of adolescent sedentary behaviors. Pediatrics 2005;116(4):908-916. 